\title{
Formation of carbon nitride compounds during successive implantations in
} copper

\author{
T. Thomé ${ }^{1}$, J. L. Colaux ${ }^{1}$, P. Louette ${ }^{2}$, G. Terwagne ${ }^{1}$ \\ ${ }^{1}$ Laboratoire d'Analyses par Réactions Nucléaires, Facultés Universitaires Notre-Dame de la \\ Paix, 61 rue de Bruxelles, B-5000 Namur, Belgium \\ ${ }^{2}$ Laboratoire Interdisciplinaire de Spectroscopie Electronique, Facultés Universitaires Notre- \\ Dame de la Paix, 61 rue de Bruxelles, B-5000 Namur, Belgium
}

\begin{abstract}
Copper substrates are successively implanted with carbon and nitrogen $\left({ }^{13} \mathrm{C}^{+}\right.$and $\left.{ }^{14} \mathrm{~N}^{+}\right)$ at high fluences $\left(5 \times 10^{17}\right.$ and $1 \times 10^{17}$ at.cm ${ }^{-2}$ respectively) in order to synthesize specific carbon nitride compounds. The concentration as well as the depth distribution of carbon ${ }^{13} \mathrm{C}$ and nitrogen ${ }^{14} \mathrm{~N}$ are determined using non resonant nuclear reactions induced by a $1.05 \mathrm{MeV}$ deuteron beam. The use of $(\mathrm{d}, \mathrm{p})$ and $(\mathrm{d}, \alpha)$ reactions allows us to profile both ${ }^{13} \mathrm{C}$ and ${ }^{14} \mathrm{~N}$ elements with a single and relatively rapid measurement and a quite good resolution. The bonded states of carbon and nitrogen are studied as a function of depth by X-ray photoelectron spectroscopy (XPS). The curve fitting of the C $1 \mathrm{~s}$ and $\mathrm{N} 1 \mathrm{~s}$ photopeaks shows that carbon and nitrogen atoms exist in different chemical states depending on the analysis depth, which correspond to specific kinds of chemical bonds. At least two characteristic C-N bonds are detected indicating that different carbon nitride compounds have been formed during the implantations.
\end{abstract}

Keywords : Carbon, Nitrogen, XPS, NRA, Implantation

Corresponding author: T. Thomé, LARN, FUNDP, 61 rue de Bruxelles, B-5000 Namur, Belgium

E-mail : tristan.thome@fundp.ac.be

Phone : 32 (0) 81725477 


\section{Introduction}

In recent years, the synthesis of crystalline carbon nitrides has been extensively investigated as they are expected to show remarkable physical properties such as wide band gap and high hardness and wear resistance. Indeed, some calculations predicted that $\alpha$ - and $\beta$ $\mathrm{C}_{3} \mathrm{~N}_{4}$ would be harder than diamond [1]. A wide variety of elaboration techniques have been used such as reactive sputtering, chemical vapour deposition, pyrolysis of organic materials, laser deposition and ion implantations [2-7]. So far, whatever the technique employed, mixed phase layers are quite often obtained and it remains very difficult to achieve fully crystalline phase formation. Some studies have also shown that fullerene-like structures can be formed from nitrogen-poor $\mathrm{CN}_{\mathrm{x}}$ phase [8]. For instance, carbon nitride systems close to the $\mathrm{C}_{11} \mathrm{~N}_{4}$ stoichiometry, that present interesting mechanical properties as high compliance, have been found to be stable [9]. Although ion implantation may be one solution to synthesize these types of new compounds due to the possibility to control precisely the modifications on surface properties of materials, successive carbon and nitrogen implantations in metals have not yet succeeded in that way [10]. Nevertheless, even amorphous carbon nitride layers have suitable physical properties for the use in many tribological applications, for instance as protective coatings.

The aim of our study is to form at least homogeneous, reproducible and well characterized carbon nitride compounds by means of implantation. We performed successive implantations of ${ }^{13} \mathrm{C}$ and ${ }^{14} \mathrm{~N}$ into copper at $200^{\circ} \mathrm{C}$ using a $2 \mathrm{MV}$ Tandetron accelerator. Then, we determined the concentration depth distributions of carbon ${ }^{13} \mathrm{C}$ and nitrogen ${ }^{14} \mathrm{~N}$ using non resonant nuclear reactions (NRA) induced by a $1.05 \mathrm{MeV}$ deuteron beam. To obtain information on the nature of the chemical bonds created between atoms in the carbon-nitride layer formed, we carried out XPS measurements.

\section{Experimental}

\subsection{Materials and substrate implantation}

The samples are polished polycrystalline copper substrates. Successive carbon ${ }^{13} \mathrm{C}^{+}$and nitrogen ${ }^{14} \mathrm{~N}^{+}$implantations were carried out using the 2 MV ALTAIS Tandetron accelerator (Accélérateur Linéaire Tandetron pour l'Analyse et l'Implantation des Solides). During both implantations, the sample was maintained at $200^{\circ} \mathrm{C}$ using a specific sample heater and the 
vacuum pressure did not exceed $10^{-5} \mathrm{~Pa}$. The implantation of carbon was performed in first place. It was implanted at $400 \mathrm{keV}$ with a current density of about $6 \mu \mathrm{A} \cdot \mathrm{cm}^{-2}$ and the final dose was $5 \times 10^{17}$ at. $\mathrm{cm}^{-2}$ over a $5 \times 5 \mathrm{~mm}^{2}$ area. The nitrogen implantation was performed at $450 \mathrm{keV}$ with a current density of $4 \mu \mathrm{A} . \mathrm{cm}^{-2}$ and the final dose was $10^{17} \mathrm{at}_{\mathrm{cm}} \mathrm{cm}^{-2}$ (on the same area). The energies of nitrogen and carbon ions were chosen to obtain identical implantation projected ranges close to $450 \mathrm{~nm}$ in copper, according to SRIM code calculations [11].

\subsection{Characterization}

The concentration as well as the distribution of carbon ${ }^{13} \mathrm{C}$ and nitrogen ${ }^{14} \mathrm{~N}$ were determined using non resonant nuclear reactions induced by a $1.05 \mathrm{MeV}$ deuteron beam before and after the ${ }^{14} \mathrm{~N}$ implantation. NRA experiments were performed using the same facilities as for the implantations (ALTAIS Tandetron accelerator). We considered the nuclear reactions ${ }^{14} \mathrm{~N}\left(\mathrm{~d}, \mathrm{p}_{0}\right){ }^{15} \mathrm{~N},{ }^{14} \mathrm{~N}\left(\mathrm{~d}, \mathrm{p}_{12}\right){ }^{15} \mathrm{~N},{ }^{14} \mathrm{~N}\left(\mathrm{~d}, \mathrm{p}_{3}\right){ }^{15} \mathrm{~N},{ }^{14} \mathrm{~N}\left(\mathrm{~d}, \alpha_{1}\right){ }^{12} \mathrm{C}$, and ${ }^{13} \mathrm{C}\left(\mathrm{d}, \mathrm{p}_{0}\right){ }^{14} \mathrm{C}$ to depth

profile ${ }^{14} \mathrm{~N}$ and ${ }^{13} \mathrm{C}$, and ${ }^{12} \mathrm{C}\left(\mathrm{d}, \mathrm{p}_{0}\right){ }^{13} \mathrm{C}$ to determine the quantity of ${ }^{12} \mathrm{C}$ carbon contamination brought during implantation. Two silicon surface barrier detectors were placed at $150^{\circ}$ and $165^{\circ}$ relative to the incident beam to measure respectively NRA and RBS signals. A $12 \mu \mathrm{m}$ mylar absorber foil was set in front of the NRA detector at $150^{\circ}$ in order to stop backscattered ions and to measure $\alpha$ and proton energies. Since the cross sections of the nuclear reactions on ${ }^{14} \mathrm{~N}$ and ${ }^{13} \mathrm{C}$ are very low, we used a large solid angle $(25.7 \mathrm{msr})$ for this detector to minimize the acquisition time (about $20 \mathrm{~min}$ ). The RBS detector was collimated $(0.18 \mathrm{msr})$ to allow the detection of backscattered deuterons without any absorber foil. The $\alpha$ and protons emitted from nuclear reactions at low energy were also detected with a better resolution than with the NRA detector. The RBS detector was used as a monitor to determine the concentrations of nitrogen and carbon atoms implanted in the copper sample from the quantity of incident deuterons detected. The distribution homogeneity of carbon and nitrogen was controlled carrying out several measurements on the implanted area of the sample.

XPS measurements were performed to study the composition and the nature of the carbon-nitride layer formed in the implanted copper sample. XPS spectra were recorded with a SSX 100 Spectrometer system (Surface Science Instrument) equipped with a hemispherical electron analyser. All reported spectra were recorded at a $35^{\circ}$ take-off angle relative to the substrate using monochromatized $\mathrm{Al} \mathrm{K} \alpha$ radiation as excitation source $(1486.6 \mathrm{eV})$. Nominal resolution was measured as full width at half maximum of 1.0 and $1.7 \mathrm{eV}$ for core-levels and 
survey spectra, respectively. The argon ion gun used for sputtering was equipped with a special regulating system which enabled automated operation during long time depth profile procedures. The depth profiling conditions were the followings: raster size of about $2 \times 2 \mathrm{~mm}^{2}, \mathrm{Ar}^{+}$ion energy of $4 \mathrm{keV}$ and sputter rates around $3 \mathrm{~nm} \cdot \mathrm{min}^{-1}$. Depth calibration was done measuring the crater depth generated by argon sputtering on the copper sample. The chemical composition was obtained from the areas of the detected XPS peaks in the C 1s, $\mathrm{N} 1 \mathrm{~s}, \mathrm{O} 1 \mathrm{~s}$ and $\mathrm{Cu} 2 \mathrm{p} 3 / 2$ regions, performing Shirley background subtraction and taking into account sensitivity factors for each constituent. The analyzed core-level lines were referenced with respect to the component $\mathrm{C}$ 1s binding energy. The peaks were analysed using mixed Gaussian-Lorentzian curves (90\% of Gaussian character). Binding state information was determined from chemical shifts observed on the binding energy scale after the curve fitting of XPS peaks.

\section{Results and discussion}

We first present NRA results from carbon and nitrogen nuclear reactions with the $1.05 \mathrm{MeV}$ deuteron beam. Then, the formation of characteristic carbon nitrogen bonds in the implanted layer is discussed on the basis of XPS measurements.

Fig. 1 shows the experimental NRA spectrum measured at $150^{\circ}$ after carbon and nitrogen implantations. A very intense peak is observed just below $3 \mathrm{MeV}$, which can be attributed to ${ }^{12} \mathrm{C}$ surface contamination. Around $6 \mathrm{MeV}$, the $(\mathrm{d}, \mathrm{p})$ peak corresponds to the implanted ${ }^{13} \mathrm{C}$ ions. All the other peaks are assigned to $(\mathrm{d}, \mathrm{p})$ and $(\mathrm{d}, \alpha)$ reactions with ${ }^{14} \mathrm{~N}$ element. From this spectrum, we determined the total concentrations and the depth distributions of ${ }^{12} \mathrm{C},{ }^{13} \mathrm{C}$ and ${ }^{14} \mathrm{~N}$ elements using the SIMNRA program [12] in which specific nuclear reaction cross sections are considered and the copper sample is sliced into layers containing all the elements concerned. The simulated SIMNRA spectrum is represented in Fig. 1 and the different concentration depth distributions of ${ }^{12} \mathrm{C},{ }^{13} \mathrm{C}$ and ${ }^{14} \mathrm{~N}$ calculated are shown in Fig. 2.

The ${ }^{13} \mathrm{C}$ depth distribution determined before the ${ }^{14} \mathrm{~N}$ implantation is slightly narrower than the final one but both areas are identical (distributions not shown here) [13], which means that a small carbon diffusion process occurs during the nitrogen implantation. 
Although ${ }^{13} \mathrm{C}$ and ${ }^{14} \mathrm{~N}$ concentrations correspond well to the implanted ones expected, a large amount of ${ }^{12} \mathrm{C}$ is also detected in the sample (nearly $5 \times 10^{17}$ at. $\mathrm{cm}^{-2}$ ).

A surface contamination layer mainly composed of ${ }^{12} \mathrm{C}$ is clearly observed (about $30 \mathrm{~nm}$ wide) while almost no ${ }^{12} \mathrm{C}$ is detected around the ${ }^{13} \mathrm{C}$ and ${ }^{14} \mathrm{~N}$ implantation mean depth (Fig. 2). This contamination may be explained by some carbon build-up phenomena during implantations as no carbon is detected on the virgin sample surface. Gaussian like distribution curves are observed for ${ }^{13} \mathrm{C}$ and ${ }^{14} \mathrm{~N}$. Although the experimental distribution maxima (close to $470 \mathrm{~nm}$ in the sample) correspond well with the projected ranges calculated with SRIM program, the widths of the curves are larger than SRIM calculated ones (Table 1). That can be explained by a diffusion process of nitrogen and carbon during the implantations. The relative concentrations of ${ }^{13} \mathrm{C}$ and ${ }^{14} \mathrm{~N}$ at the profile maximum correspond to our implanted dose estimations (N/C ratio of about 0.2$)$.

Then, XPS measurements were carried out to know whether specific carbon nitrogen bonding is created in the implanted copper sample.

Survey scan XPS spectra indicate the presence of carbon, nitrogen and oxygen in the copper implanted sample. The oxygen contamination is not studied in this work because it is mainly localized in the near surface. The concentrations of nitrogen and carbon can be deduced from the areas of the different XPS peaks. The carbon contamination layer detected by NRA is confirmed by XPS results. The maximum concentration range (around $450 \mathrm{~nm}$ ) also corresponds approximately to the one determined by NRA. Nevertheless, the atomic concentration ratio of nitrogen to carbon $(\mathrm{N} / \mathrm{C})$ is less important than the one calculated from NRA experiments (by a factor 1.5). That can be explained by some contribution of the surface contamination carbon to the determination of the carbon concentration value at $450 \mathrm{~nm}$.

Core level photoelectron spectra of $\mathrm{C}$ and $\mathrm{N} 1 \mathrm{~s}$, acquired at the surface and at a depth where the concentrations of nitrogen and carbon are maximum, are presented in Fig. 3 and 4. No clear peak components can be observed in the different spectra in $\mathrm{C} 1 \mathrm{~s}$ region but the peaks broaden with the analysis depth. One main peak component, which is centred around $285 \mathrm{eV}$, can be resolved at the surface. It corresponds to $\mathrm{C}-\mathrm{C}$ bonds in an amorphous carbon contamination layer. A tail in the high binding energies indicates the presence of low quantities of $\mathrm{C}-\mathrm{N}$ and $\mathrm{C}-\mathrm{O}$ bonds (a few \%) due to the higher electronegativity of nitrogen and oxygen. When, the analysis goes further in depth, the peak broadening is accompanied with an increase of the tail component intensity. To achieve curve fitting of the $\mathrm{C} 1 \mathrm{~s}$ peak at the $450 \mathrm{~nm}$ depth, four gaussian components $\left(\mathrm{C}_{0}, \mathrm{C}_{1}, \mathrm{C}_{2}, \mathrm{C}_{3}\right)$ have been used, that we attributed to different bonding states of carbon atoms. The $\mathrm{C}_{0}$ component (around $284.8 \mathrm{eV}$ ) is attributed to 
carbon atoms bonded to carbon neighbours, as in graphite or amorphous carbon. No distinction between $\mathrm{sp}^{2}$ and $\mathrm{sp}^{3}$ has been made for this first component whatever the analysis depth. $\mathrm{C}_{1}(286.2 \mathrm{eV})$ and $\mathrm{C}_{2}(287.8 \mathrm{eV})$ peak components are related to nitrogen presence. As suggested in different reports $[14,15]$, we ascribed $\mathrm{C}_{1}$ to $\mathrm{sp}^{2} \mathrm{C}-\mathrm{N}$ bonds (trigonal carbon configuration) and $\mathrm{C}_{2}$ to $\mathrm{sp}^{3} \mathrm{C}-\mathrm{N}$ bonds (tetrahedral carbon configuration). The final peak component with the highest binding energy $(289.9 \mathrm{eV})$ may be assigned to C-O bonds. The position and the intensity of this last peak are rather difficult to obtain precisely as they depend very much on the background subtraction procedure. Thus, the presence of $\mathrm{C}-\mathrm{O}$ bonds is not discussed here.

As shown in Fig. 4, the N 1s core level photoelectron spectra exhibit more resolved peak components even if their intensities are lower due to a smaller implanted concentration. No curve fitting and decomposition were performed on the first spectrum because of poor statistics due to very low nitrogen concentration detected at the surface. To perform curve fitting of the $\mathrm{N}$ 1s peak at the $450 \mathrm{~nm}$ depth, three gaussian components $\left(\mathrm{N}_{0}, \mathrm{~N}_{1}, \mathrm{~N}_{2}\right)$ have been used. We attributed the $\mathrm{N}_{0}(398.7 \mathrm{eV})$ and $\mathrm{N}_{1}$ (around $400.7 \mathrm{eV}$ ) dominant peak components to respectively, $\mathrm{sp}^{3} \mathrm{C}-\mathrm{N}$ bonds (nitrogen atom bonded to tetrahedral carbon) and to $\mathrm{sp}^{2} \mathrm{C}-\mathrm{N}$ bonds (nitrogen atom bonded to trigonal carbon). A small contribution in the highest binding energies (around $403.7 \mathrm{eV}$ ) can also be detected. We assigned it to N-O bonds and we will not discuss it further. This peak component identification for $\mathrm{C} 1 \mathrm{~s}$ and $\mathrm{N} 1 \mathrm{~s}$ core level photoelectron spectra is in good agreement with recent reports in literature $[15,16]$.

These results show that several carbon nitride compounds are created during the successive implantations. At least two kinds of carbon nitride regions, that are characterized by different hybridisations of $\mathrm{C}-\mathrm{N}$ bonds $\left(\mathrm{sp}^{2}\right.$ and $\left.\mathrm{sp}^{3}\right)$, mixed in a dominant amorphous carbon matrix and surrounded by copper, may be envisioned.

\section{Conclusion}

This study showed that carbon nitride formation was possible by performing successive carbon and nitrogen implantations at $200^{\circ} \mathrm{C}$. The atomic depth distributions of nitrogen and carbon were determined by NRA. The depth profile peaks corresponded well to the calculated ion projected ranges (around $470 \mathrm{~nm}$ for both profiles), which enabled us to maximize the interactions of nitrogen and carbon at this depth. XPS measurements clearly indicated that characteristic types of chemical bonds between carbon and nitrogen atoms were created at this depth and that they might correspond to $\mathrm{sp}^{3}$ and $\mathrm{sp}^{2}$ carbon hybridisations. These results 
suggest that at least two different carbon nitride regions exist and that they are embedded in a dominant amorphous carbon matrix.

\section{Acknowledgments}

T. Thomé was granted a CERUNA post-doctoral position by the University of Namur (FUNDP). 


\section{References}

[1] A. Lui, M. Cohen, Science 247 (1989) 688

[2] K.M. Yu, M.L. Cohen, B.E. Haller, W.L. Hansen, A.Y. Liu, J.C. Wu, Phys. Rev. B 49 (1994) 5034

[3] L. Maya, D.R. Cole, E.W. Hagaman, J. Am. Ceram. Soc. 74 (1991) 1686

[4] C. Niu, Y.Z. Lu, C.M. Lieber, Science 261 (1993) 334

[5] E. Gyorgy, V. Nelea, I. Mihailescu, A. Perrone, H. Pelletier, A. Cornet, S. Ganatsios, J. Werckmann, Thin Solid Films 388 (2001) 93

[6] A. Hoffman, I. Gouzman and R. Brener. Appl. Phys. Lett. 64 (1994), 845

[7] E. Romanowsky, O. Bespalova, A. Borisov, N. Goryaga, V. Kulikauskas, V. Sukharev, V. Satekin, Nucl. Instr. Meth. B 139 (1998) 355

[8] N. Hellgren, M.P. Johansson, E. Broitman, L. Hultman and J.-E. Sundgren. Phys. Rev. B 59 (1999) 5162

[9] H. Sjöström, L. Hultman, J.-E. Sundgren, S. Hainsworth, T. Page, G. S. Theunissen, J. Vac. Sci. Technol., A 14 (1996) 56

[10] R. Sanchez, J. A. Garcia, A. Medrano, M. Rico, R. Martinez, R. Rodriguez, C. Fernandez-Ramos, A. Fernandez, Surface and Coatings Technology 158-159 (2002) 630

[11] J.F. Ziegler, J.P. Biersack, U. Littmark, The Stopping and Range of Ions in Solids, Pergamon, New York, 1967

[12] M. Mayer, SIMNRA, a Simulation Program for the Analysis of NRA, RBS and ERDA, Proc. $15^{\text {th }}$ Int. Conf. Appl. Accelerators in Research and Industry, J. L. Duggan and I. L. Morgan (eds.), AIP Conf. Proc. 475 (1999) 541

[13] J. Colaux, G. Terwagne, Nucl. Instr. Meth. B 240 (2005) 429

[14] B. Angleraud, N. Mubumbila, P. Y. Tessier, V. Ferandez, G. Turban, Diamond and Rel. Mat. 10 (2001) 1142

[15] N. Hellgren, J. Guo, Y. Luo, C. Sathe, A. Agui, S. Kashtanov, J. Nordgren, H. Agren, J. E. Sundgren, Thin Solid Films 471 (2005) 19

[16] S.E. Rodil, S. Muhl, Diamond and Related Materials 13 (2004) 1521 


\section{Tables}

Table 1: Experimental and calculated projected ranges ( $\mathrm{R}_{\exp }$ and $\left.\mathrm{R}_{\mathrm{SRIM}}\right)$ and full widths at half maximum $\left(\mathrm{FWHM}_{\exp }\right.$ and $\left.\mathrm{FWHM}_{\mathrm{SRIM}}\right)$ of the concentration distributions in the copper sample implanted with ${ }^{13} \mathrm{C}^{+}$and ${ }^{14} \mathrm{~N}^{+}$at respectively 400 and $450^{\circ} \mathrm{keV}$.

\begin{tabular}{|c|c|c|c|c|}
\hline Element & $\mathrm{R}_{\exp }(\mathrm{nm})$ & $\mathrm{R}_{\text {SRIM }}(\mathrm{nm})$ & FWHM $_{\exp }(\mathrm{nm})$ & FWHM $_{\text {SRIM }}(\mathrm{nm})$ \\
\hline${ }^{13} \mathrm{C}$ & 480 & 450 & 350 & 130 \\
\hline${ }^{14} \mathrm{~N}$ & 460 & 430 & 300 & 130 \\
\hline
\end{tabular}




\section{Figure captions}

Figure 1: Experimental and simulated NRA spectra of the copper sample implanted with ${ }^{13} \mathrm{C}^{+}$ and ${ }^{14} \mathrm{~N}^{+}$at $200^{\circ} \mathrm{C}$ measured at $150^{\circ}$ (NRA detector). Symbols (diamonds) and solid lines represent respectively the experimental spectrum and the simulated one with SIMNRA program.

Figure 2: Concentration depth distributions of ${ }^{12} \mathrm{C}$ (open squares), ${ }^{13} \mathrm{C}$ (open circles) and ${ }^{14} \mathrm{~N}$ (open triangles) calculated from SIMNRA simulations for the copper sample implanted with ${ }^{13} \mathrm{C}^{+}$and ${ }^{14} \mathrm{~N}^{+}$at $200{ }^{\circ} \mathrm{C}$. Solid lines are guides for the eyes.

Figure 3: C 1s XPS spectra at the surface (a) and at a $450 \mathrm{~nm}$ depth (b) for the copper sample implanted with ${ }^{13} \mathrm{C}^{+}$and ${ }^{14} \mathrm{~N}^{+}$at $200{ }^{\circ} \mathrm{C}$. Experimental data are represented by open squares. Solid lines are the results of the curve fitting gaussian components in dotted lines. Meaning of $\mathrm{C}_{\mathrm{i}}$ notations is discussed in the text.

Figure 4: N 1s XPS spectra at the surface (a) and at a $450 \mathrm{~nm}$ depth (b) for the copper sample implanted with ${ }^{13} \mathrm{C}^{+}$and ${ }^{14} \mathrm{~N}^{+}$at $200{ }^{\circ} \mathrm{C}$. Experimental data are represented by open squares. Solid lines are the results of the curve fitting gaussian components in dotted lines. Meaning of $\mathrm{N}_{\mathrm{i}}$ notations is discussed in the text. 


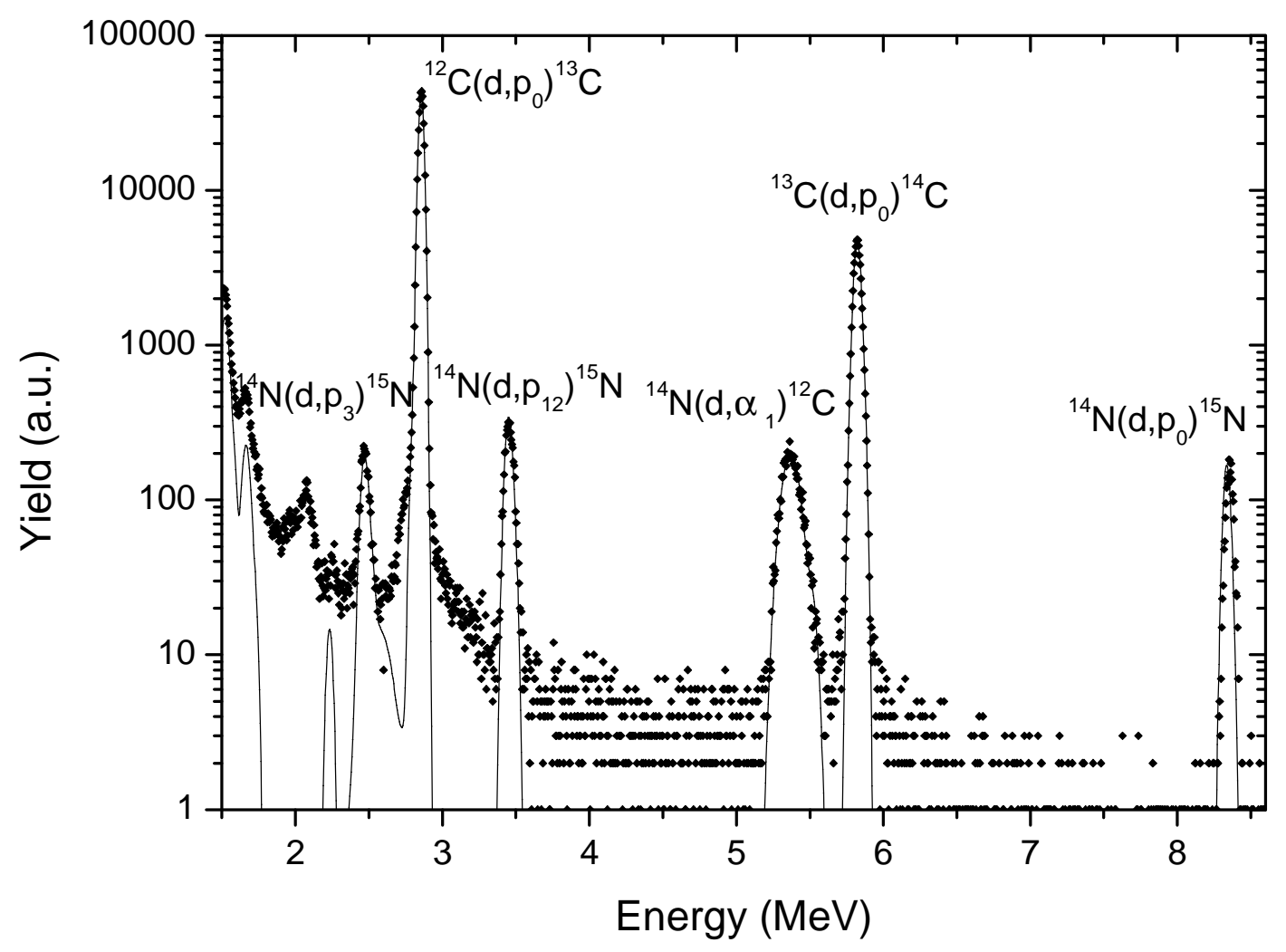

Figure 1 

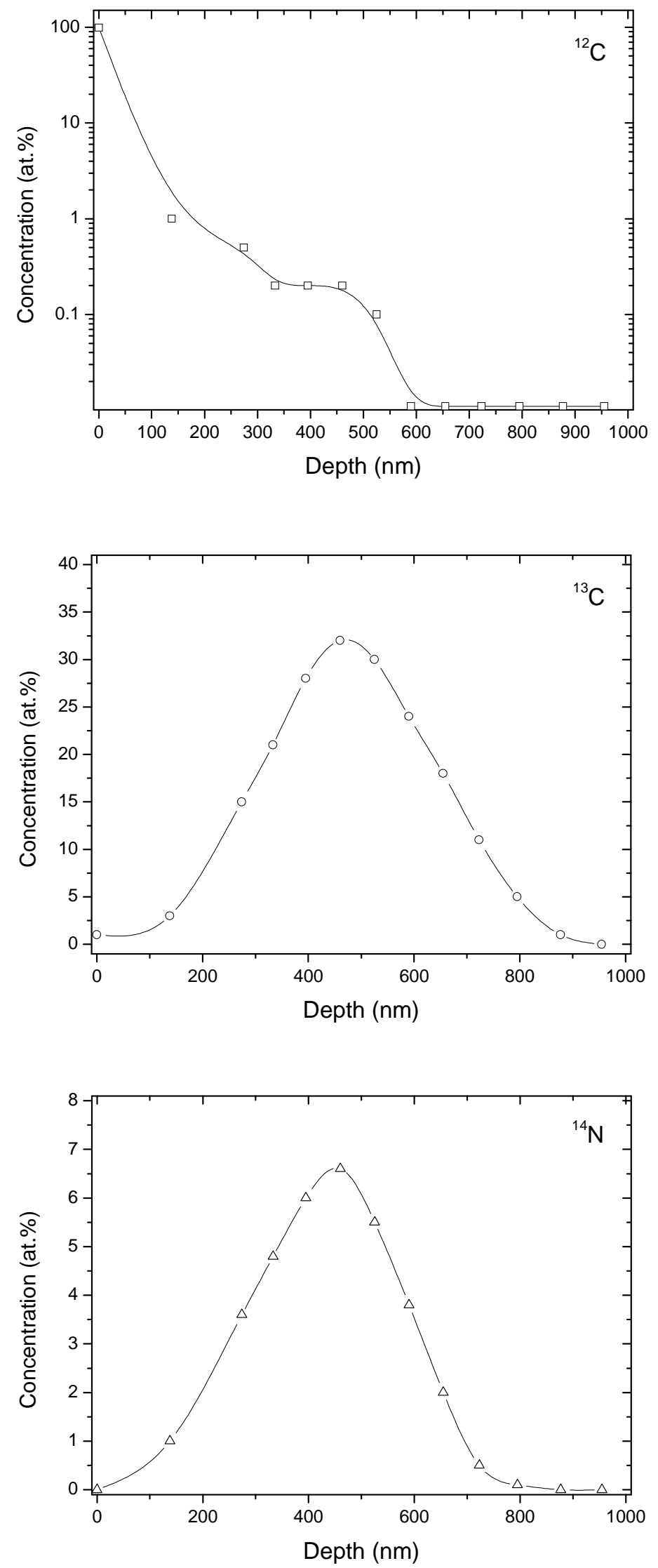

Figure 2 

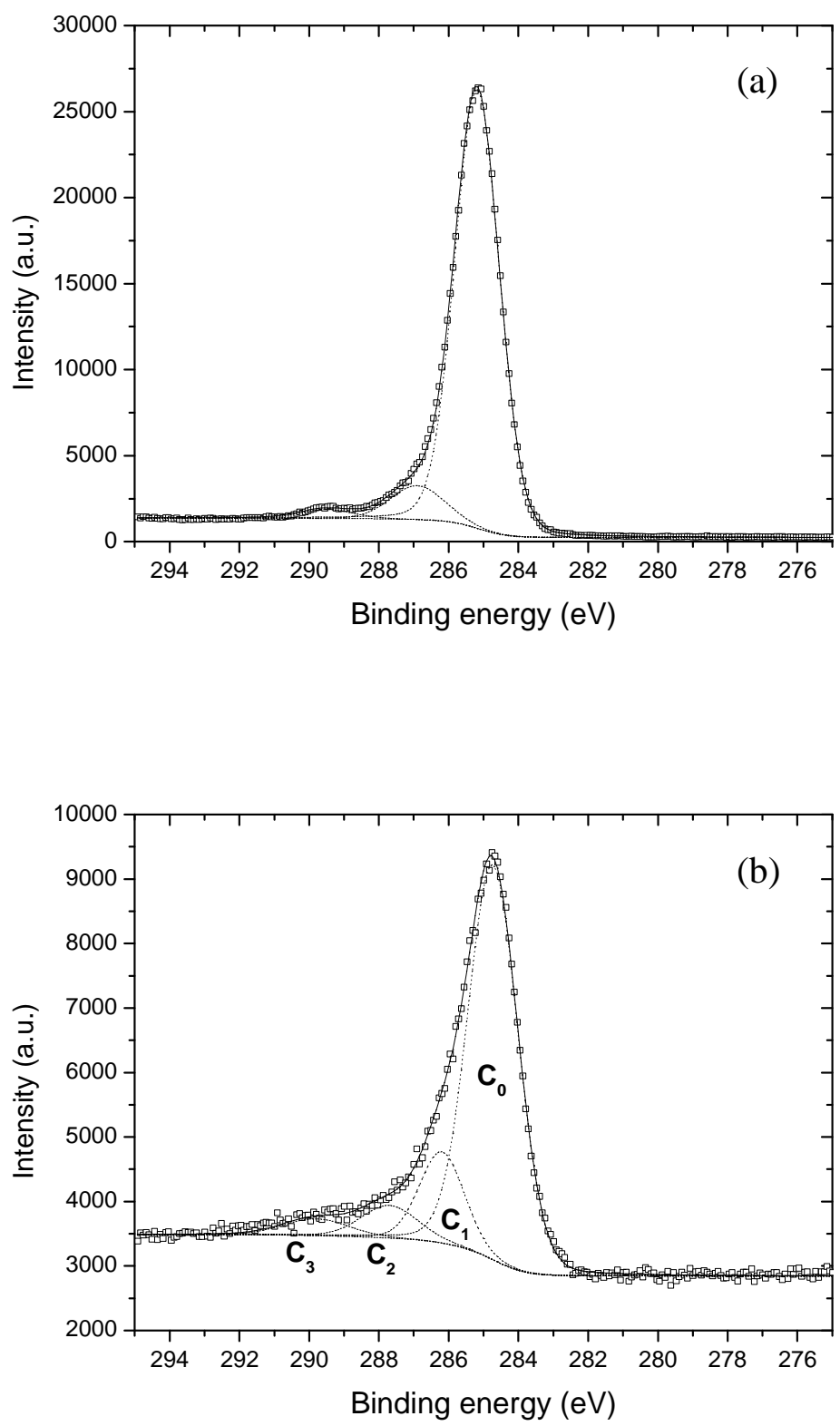

Figure 3 

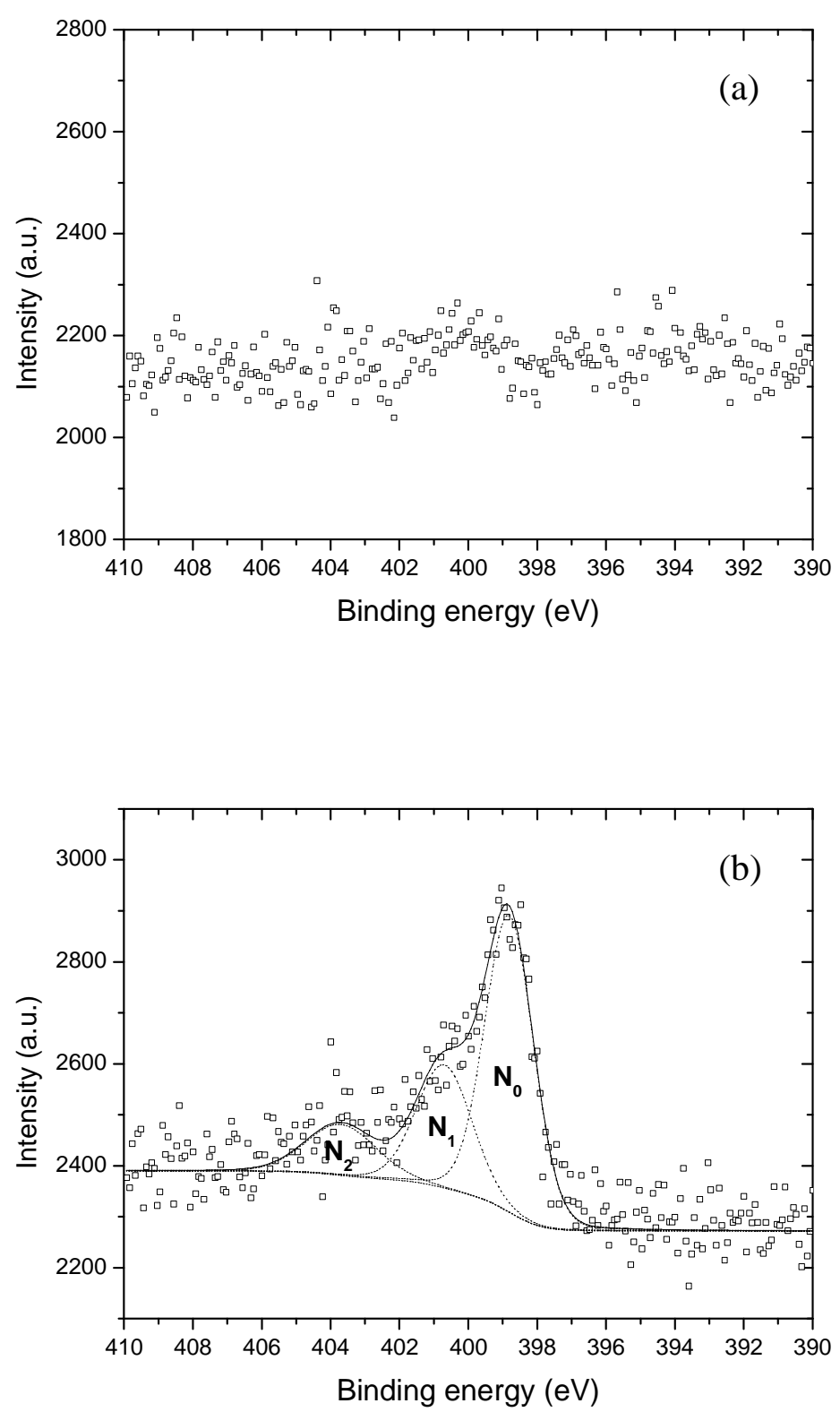

Figure 4 